\title{
Design and simulation of low side lobe micro-strip array antenna at multiple frequencies
}

DOI:10.36909/jer.11731

\author{
Junaid Jamshid*, Kamlesh Narwani****, Aftab Ul Nabi*****, Saifullah Adnan*, Mushtaq \\ Ahmed*
}

\author{
*School of Information and Communication Engineering, Shanghai University. \\ **School of Electronic Information \& Communication, Huazhong University of Technology, \\ China.
}

***School of Electronics \& Information Engineering, South China University of Technology, China.

*Email: kdnarwani@ hotmail.com; Corresponding Author.

\begin{abstract}
In this paper, we present a simple design of a feed network for the antenna to achieve a lower side lobe level. Side Lobe Levels (SLL) are critical issues in the detection of an object. Higher side lobe levels can increase the false detection of objects in an autonomous vehicle system. The array is designed and simulated for four different frequencies, one at a time to make it a scalable design. The chosen frequencies are $10 \mathrm{GHz}, 15 \mathrm{GHz}, 20 \mathrm{GHz}$, and $24 \mathrm{GHz}$. The feed network design consists of eight patch elements with an equal power divider and CST studio software is used for simulations. From simulation results, it can be observed that VSWR is equal to 1.26, $1.16,1.62$, and 1.05 at respective frequencies. So, the radiation efficiency can be achieved as $1.14 \mathrm{~dB},-0.92 \mathrm{~dB},-0.46 \mathrm{~dB},-0.41 \mathrm{~dB}$. The results substantiate that proposed design can reduce the SLL more than $-24.5 \mathrm{~dB}$ in the elevation plane and also it is greater than $14.4 \mathrm{~dB}$ at all the
\end{abstract}


aforementioned frequencies.

Keywords: high gain; low side lobe; VSWR; CST; SLL.

\section{INTRODUCTION}

The facile fabrication, low profile, weight, and low-cost PCB manufacturing have made microstrip patch antennas extremely significant antenna type of meeting many applications in the field of radar systems, aircraft, automotive applications, and others (Karimi \& Maddahali, 2018). In autonomous vehicle (AV), the sensing module uses various sensor information (Radar, Lidar, and camera information), to indicate the obstacles on the path relevant to the driving scenario. Radar systems work in wideband frequencies from $300 \mathrm{MHz}$ to $100 \mathrm{GHz}$. The higher frequency in any radar system can be affected more by weather conditions such as rain or clouds. However, the higher the transmitted frequency, the better is the accuracy of the radar system (Rabbani \& Ghafouri-Shiraz, 2017). In fact the most important thing is the matching the impedances of micro-strip patches which has been improved by using different unique matching networks (Anandkumar \& Sangeetha, 2020; Rajeswari \& Anbalagan, 2020; Sohail et al., 2018).

A large wideband array, containing twelve radiating elements with double-layer substrate integrated waveguide is presented in (Wang et al., 2018). Different kinds of power divider with unequal T-junction have been reviewed in (Ahn \& Tentzeris, 2019; J. Ji et al., 2020; Quan et al., 2021) Taylor distribution is used for reducing the side lobe level, and achieve side lobe level of $23.9 \mathrm{~dB}$ in the E-plane and $20.5 \mathrm{~dB}$ in the H-plane at the center frequency. In (Liu et al., 2015), an array is presented to enhance the gain for millimeter-wave applications; the array evaluates the substrate height for gain enhancement. The paper shows that a long feeding line can increase the loss, and thick substrate degrades the antenna gain. On the other hand, a relatively thin substrate can enhance the gain, but narrower bandwidth and higher side lobe levels are also introduced in 
the array antenna. (Oborzhytskyy \& Prudyus, 2016) states that side lobe level ratios are essential to reduce false indications of objects in radars, and autonomous applications. So much research is being carried out on minimizing the side lobe levels. Many researchers such as (Gasztold, 2014) have proposed different solutions to eliminate the problems caused by SLL. Power divider feed networks have been mostly used for minimizing the side lobes levels. Various types of power dividers proposed with unequal and equal T-junction feed networks have been designed and reviewed in (Park et al., 2016).

In this paper, a patch array antenna is created and simulated for different frequencies, patch antenna constructed with a couple of slots near the radiating edges. After creating a patch, a uniform power divider is created for equal power distribution in the feed network. The detailed construction and mathematical expression are presented in the previous article (Jamshid et al., 2017). Here we modify the array to make it scalable for different frequencies. The array is simulated at four different frequencies, one by one, to make it a scalable design. The frequencies of $10 \mathrm{GHz}, 15 \mathrm{GHz}, 20 \mathrm{GHz}$, and $24 \mathrm{GHz}$ are selected for simulation. The simulation shows that simulated VSWR we can calculate is almost equal to $1.26,1.16,1.62$, and 1.05 , and the radiation efficiency is equal to $-1.14 \mathrm{~dB},-0.92 \mathrm{~dB},-0.46 \mathrm{~dB},-0.41 \mathrm{~dB}$ at selected frequencies. Also, the SLL achieved is more than $-24 \mathrm{~dB}$.

The remainder of the paper is organized as follows: Proposed array design is elaborated in the section 2. Section 3 demonstrates the simulation results at different scenarios of multiple frequencies. Finally, the conclusion along with the future work is drawn in section 4.

\section{RELATED WORK}

(Smolders \& Visser, 2014) present a novel method for low sidelobe and control of axial ratio of circularly-polarized (CP) phased array antennas. A novel random sequential rotation (RSR) 
provides the properties likely as randomly-spaced array antennas. Wider band is achieved, without the creation of grating lobes. In contrast, antenna gain improved using a uniform amplitude distribution. Infact the interspacing of element is much higher than $\lambda / 2$ but it wellcontrolled sidelobes. In the diagonal-plane the measured cross-polarization level is down below $20 \mathrm{db}$ at a 20 o scan angle.

(Yang et al., 2019) proposed a hybrid technique for 3D pattern synthesizing of antenna to achieve the low side-lobe level for truncated-cone arrays. For this technique, truncated-cone conformal phased arrays units were projected at a tangent plane of the cone. At that time, a 2 D optimization of Chebyshev amplitude distribution was used in 2 different direction of the tangent plane. In keeping with mind the position of the units, the amplitude of excitation current for every unit over the conformal design is originated reversely, after that the amplitude of excitation current is furtherly optimize by employing the genetic algorithm (GA). A study of sidelobe level of $35 \mathrm{~dB}$ and 3-dimentional pattern is done by using this truncated cone with 8 by 8 units over it. (P. Ji et al., 2020) presented an array of microstrip for $24 \mathrm{GHz}$ frequency, with a single layer of substrate of electrically thin width to provide a solution regarding cost, ehnaced impedance bandwidth etc for automotive application. a prototype of array construct for a predefined sidelobe level - $25 \mathrm{~dB}$ in $\mathrm{E} \& \mathrm{H}$-plane.In contrast, the realized gain $=22.5 \mathrm{dBi}$, for centeral frequency and although more than $-21 \mathrm{dBi}$ for a $1 \mathrm{Ghz}$ band of frequency. At the end, the resultant sidelobe in $\mathrm{E}$ plane is $20 \mathrm{~dB}$ and $18 \mathrm{~dB}$ for H-plane. (Shin et al., 2013) proposed a novel array antenna design for low sidelobe. It is having a number of 18 elements, with gap coupled antenna to acheive a low radiation coefficient and is used for high radiation coefficient. Polarization of 450 is used to reduce the interference. The antenna has $20.8 \mathrm{dBi}$ gain and sidelobe level of elevation direction is under -20dB. 


\section{PROPOSED ARRAY DESIGN}

Construction of patch design, feed network design, and all related mathematical expression is describing in the previous article (Jamshid et al., 2017), some of them presented here. That paper also shows that SLL can be lower with increasing patch elements from four elements to eight elements.

$$
\begin{aligned}
& W=\frac{c}{2 f_{0} \sqrt{\frac{\varepsilon_{r}+1}{2}}} \\
& \varepsilon_{\text {eff }}=\frac{\left(\varepsilon_{r}+1\right)}{2}+\frac{\left(\varepsilon_{r}-1\right)}{2}\left[\left(\frac{1}{\sqrt{1+\frac{12 h}{w}}}\right)\right] \\
& L=\frac{c}{2 f_{0} \sqrt{\varepsilon_{\text {eff }}}}-0.824 h \frac{\left(\varepsilon_{\text {eff }}+3\right)\left(\frac{W}{h}+0.264\right)}{\left(\varepsilon_{\text {eff }}-0.258\right)\left(\frac{W}{h}+0.8\right)} \\
& Z_{0}=\frac{90\left(\varepsilon_{r}{ }^{2}-1\right)}{\varepsilon_{r}\left(\frac{L}{W}\right)^{2}} \\
& Z_{\text {inr }}=Z_{0} \cos \left(p i * \frac{R}{L}\right)^{2}
\end{aligned}
$$

Where $W=$ patch width, $f_{o}=$ operating frequency, $L=$ patch length, $h=$ substrate height or thickness, $c=$ velocity of free space, $Z_{o}=$ impedance with no inset-fed, $Z_{\text {inr }}=$ impedance of insetfed, and $\varepsilon_{\text {eff }}=$ effective di-electric constant.

Now, this paper concentrates upon modification into the design to tune it at different frequencies. Initially, $24 \mathrm{GHz}$ is the operating frequency for autonomous vehicles radars. The only objective of choosing these frequencies is to check the scalability of the proposed antenna design. Here scalability means, this design can be modified and tuned at a range from $10-24 \mathrm{GHz}$ as desired. 
We should recalculate the parameter's dimensions for the desired frequency. As we know from the literature, the operating frequency of a patch antenna depends upon the patch antenna length. Hence, the dimension of the presented array antenna for different frequencies is listed down in Table 1.

Table 1 Component list with measurements

\begin{tabular}{|l|l|l|l|l|l|}
\hline \multirow{2}{*}{ Detail of components } & \multirow{2}{*}{$\begin{array}{l}\text { Uymbol } \\
\text { Length of line }\end{array}$} & \multicolumn{2}{|l|}{ Value (mm) } \\
\cline { 3 - 6 } & L1 & $\mathbf{1 0 G H z}$ & $\mathbf{1 5 G H z}$ & $\mathbf{2 0 G H z}$ & $\mathbf{2 4 G H z}$ \\
\hline Width of line & WL1 & 0.0 & 3.7 & 2.9 & 2.45 \\
\hline Length of slot1 & LS1 & 8.4 & 5.1 & 3.8 & 3.0 \\
\hline Length of slot2 & LS2 & 2.3 & 1.7 & 1.1 & 0.70 \\
\hline Length of inset-fed & Li & 2.3 & 2.1 & 1.6 & 1.25 \\
\hline Width of slot1 & WS1 & 0.6 & 0.45 & 0.32 & 0.20 \\
\hline Width of slot2 & WS2 & 1.0 & 0.8 & 0.65 & 0.40 \\
\hline Width of inset-fed & Wi & 0.6 & 0.6 & 0.60 & 0.60 \\
\hline Slot position & Ps & 0.6 & 0.4 & 0.25 & 0.20 \\
\hline Length of patch & LP & 9.5 & 6.1 & 4.6 & 3.84 \\
\hline Width of patch & WP & 15 & 10 & 8 & 6.6 \\
\hline
\end{tabular}

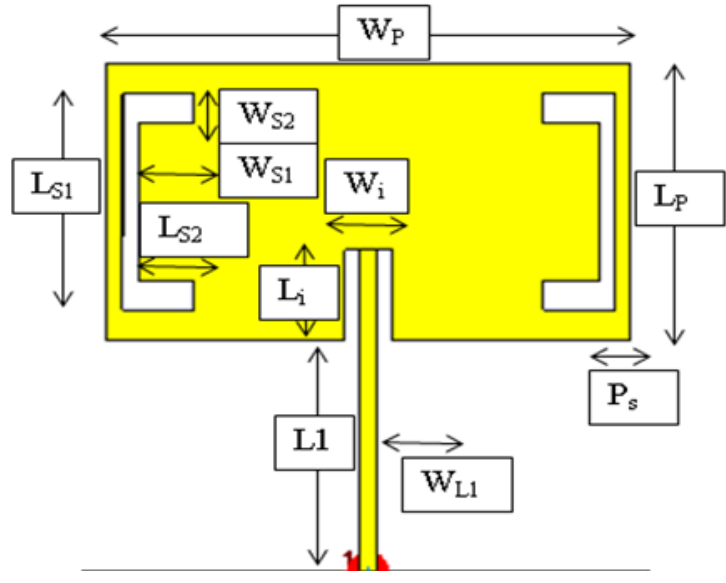

Figure 1 Proposed Inset-Fed Slotted Patch 
Figure 1 shows the proposed patch antenna with the proper naming scheme. The length of line1 is a quarter wavelength transformer used to match the impedances. The length of slot 1 depends upon the patch length. It has approximately the difference of 0.80 to 0.90 from the length of the patch. The length of slot 2 is also approximately 0.70 to 0.85 times the width of the patch. Several iterations performed to achieve the best value, which is listed in the below table. Also, it is confirmed from the research articles that the input impedance decreases rapidly when the insetfed is moved toward the center. These parametric studies have been used to derive the formula to find the exact inset length (IL) to achieve 50-ohm input impedance for the commonly used thin dielectric substrate.

$$
I L=\frac{0.001699 \varepsilon^{7}+0.13761 \varepsilon^{6}-6.1783 \varepsilon^{5}+93.187 \varepsilon^{4}-682.69 \varepsilon^{3}+2561.9 \varepsilon^{2}-4043 \varepsilon+6697}{2}(2 \leq \varepsilon \leq 10)
$$

The width of the inset is equally divided between the width of the inset line and the spacing form patch. Taylor synthesis ( $\mathrm{Li}$ et al., 2017), one of the most appropriate techniques to reduce the side lobe level of the array. From Table 2 weighted values, we simulate the proposed antenna to verify the reduction in side lobe levels. We observe that best-weighted values are in case 1, which lower side lobe level more than $-24.5 \mathrm{~dB}$. We apply the same Taylor weight values for all frequencies in the next section. The calculation of Taylor's weight function shown below.

$$
f(\xi)=1+2 \sum_{m=1}^{\bar{n}-1} g(m, A, \bar{n}) \cos m \xi
$$




$$
g(m, A, \bar{n})=\frac{[(\bar{n}-1) !]^{2}}{(\bar{n}-1+m) !(\bar{n}-1-m) !} \prod_{k=1}^{-\bar{n}-1}\left(1-\frac{m^{2}}{\sigma^{2}\left[A^{2}+\left(k-\frac{1}{2}\right)^{2}\right]}\right)
$$

$A=\frac{1}{\pi} \operatorname{arch} \eta$

$$
\sigma=\frac{\bar{n}}{\left(A^{2}+\left(\bar{n}-\frac{1}{2}\right)^{2}\right)^{\frac{1}{2}}}
$$

Where $\mathrm{A}$ is the ratio of the main beam to SLL, $\bar{n}$ is the number of Taylor weight. Generally, for Taylor distribution, $\bar{n}$ is set to 4 to maintain the side lobe level between -20 to $-30 \mathrm{~dB}$.

Table 2 Weighted values for 1x8 array

\begin{tabular}{|l|ll|l|l|l|l|}
\hline \multirow{3}{*}{ Case No } & \multicolumn{5}{|c|}{ Weight width (mm) } & \multirow{2}{*}{ Side lobe level (dB) } \\
\cline { 2 - 6 } & $\begin{array}{l}\text { w1 } \\
\text { w8 }\end{array}$ & w2 \& w7 & w3 \& w6 & w4 \& w5 & \\
\hline 1 & 1.2 & 0.75 & 0.4 & 0.2 & $-24.5 \mathrm{~dB}$ \\
\hline 2 & 1.4 & 1 & 0.6 & 0.2 & $-22 \mathrm{~dB}$ \\
\hline 3 & 1 & 0.6 & 0.4 & 0.2 & $-23 \mathrm{~dB}$ \\
\hline
\end{tabular}

\section{SIMULATION AND RESULTS}

\section{At 10GHz}

From Figure 2, we notice that the proposed array antenna is tuned at frequency $10 \mathrm{GHz}$, and the reflected power loss is almost equal to $-18.76 \mathrm{~dB}$. We also find the reflection coefficient $\Gamma=0.11$ and VSWR $=1.26$ from this figure. 

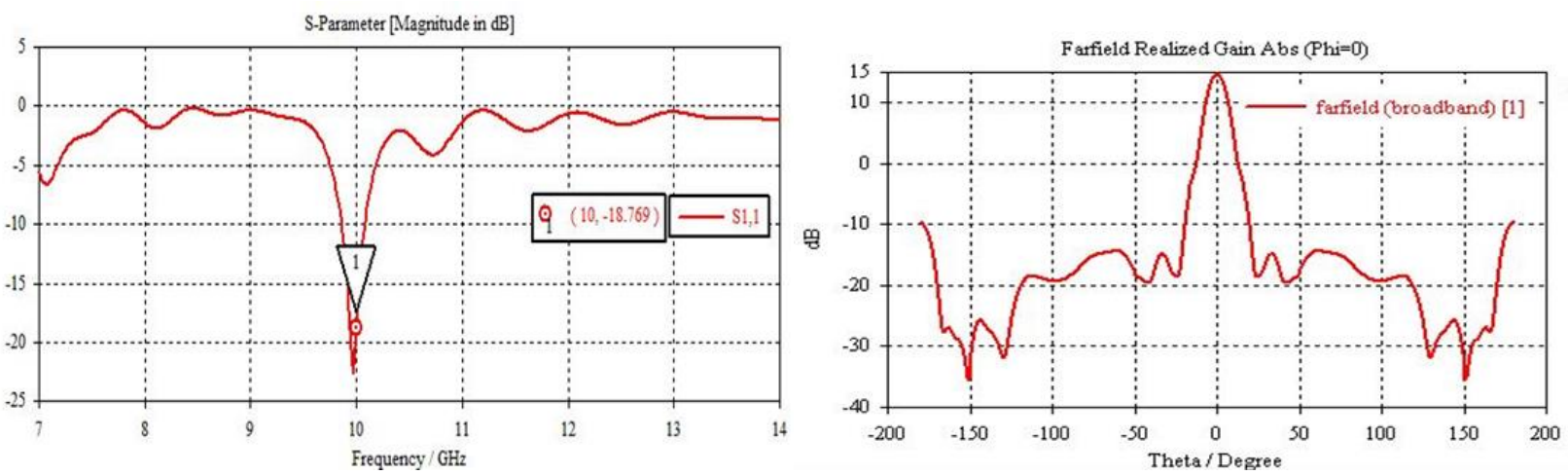

Figure 2 Proposed Antenna Frequency Response at $10 \mathrm{GHz}$ Figure 3 Side Lobe Levels $10 \mathrm{GHz}$

Simulation results also exhibit the amount of power accepted and radiated of the array antenna.

The amount of power accepted by antenna array is $-3.0 \mathrm{~dB}$, which is $0.49 \mathrm{w}$ in linear-scale, also power radiated by the antenna is $-4.2 \mathrm{~dB}(0.37 \mathrm{w}$ in linear scale). In Figure 3 , the frequency is set to $10 \mathrm{GHz}$, Main Lob Magnitude $=14.6 \mathrm{~dB}$, main lobe direction=0.06 deg, angular width $(3 \mathrm{~dB})$ $=10.7 \mathrm{deg}$, side lobe level=-24.2 dB. Furthermore, Figure 3 shows the Cartesian representation of the radiation pattern and exhibits some information about side lobe level, tuning frequency, main lobe magnitude, and direction. We observe that a side lobe level of $-24.2 \mathrm{~dB}$ is achieved with a gain of $14.6 \mathrm{~dB}$.

Figure 4 shows the graphical result of radiated efficiency and total efficiency at frequency $10 \mathrm{GHz}$. The radiated efficiency of this array is $-1.14 \mathrm{~dB}(76 \%)$ and total efficiency is $-1.2 \mathrm{~dB}(75 \%)$. Figure 5 is the $3 \mathrm{D}$ radiation pattern plot of array antenna, and from this result, we also see the realized gain, which is $14.9 \mathrm{~dB}$ at $10 \mathrm{GHz}$ frequency.

All simulation results are shown that the presented array antenna shows a good radiation pattern along with the efficiencies, powers, and gain, which are the critical features of any antenna. These parameters will justify the effectiveness of
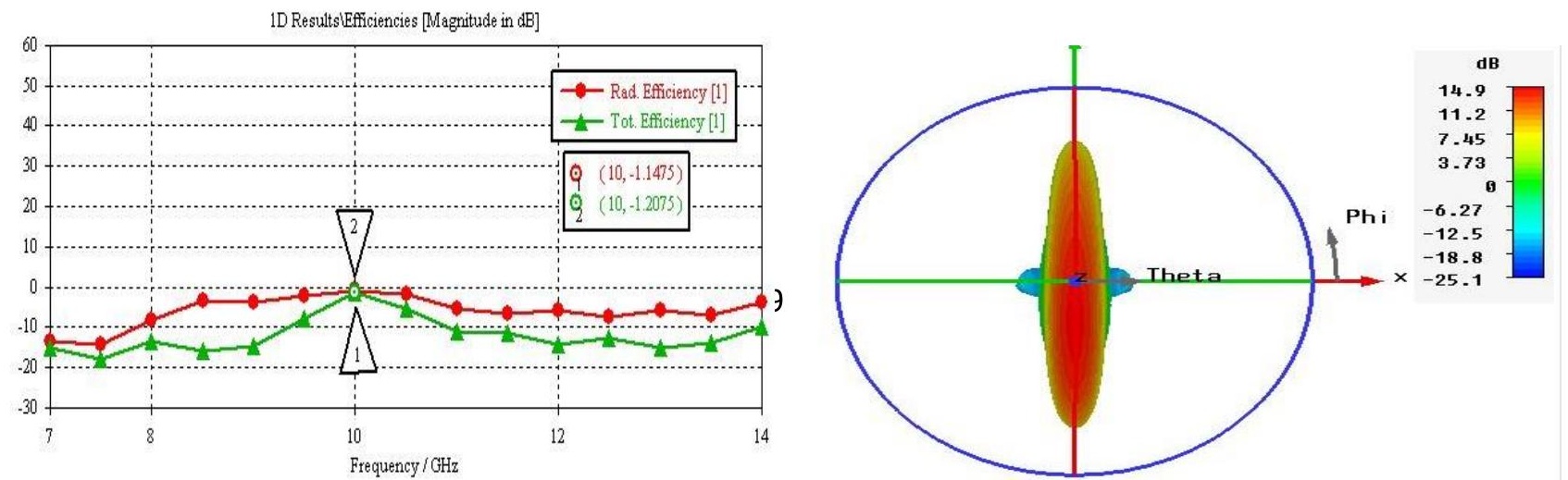
antenna in practical usage. In the next section, we perform simulation at $15 \mathrm{GHz}$ and check all these parameters to verify the scalability of the design.

Figure 3 Efficiencies of Proposed Antenna Array

Figure 4 Proposed Antenna Array Radiation

Pattern

\section{At $15 \mathrm{GHz}$}

From Figure 6 we notice that the proposed array antenna is tuned at frequency $15 \mathrm{GHz}$, and the reflected power loss is almost equal to $-22.5 \mathrm{~dB}$. We also find the reflection coefficient $\Gamma=0.074$ in linear scale and VSWR $=1.16$ from this figure.

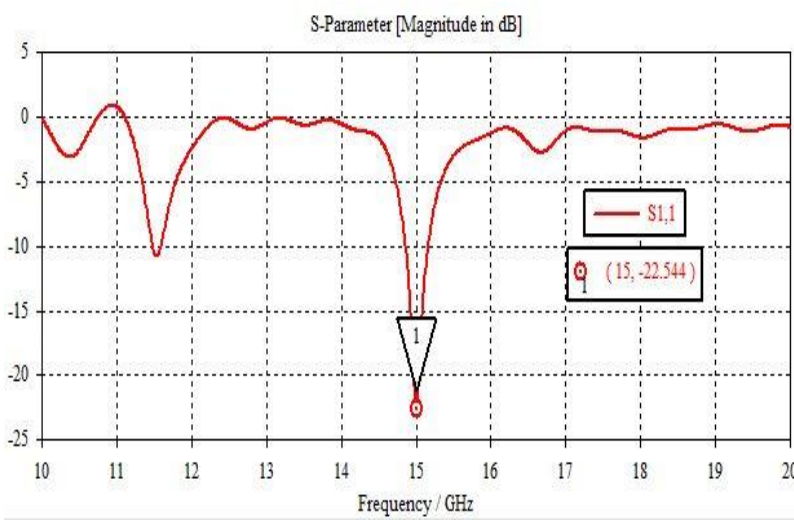

Figure 5 Frequency Response at $15 \mathrm{GHz}$

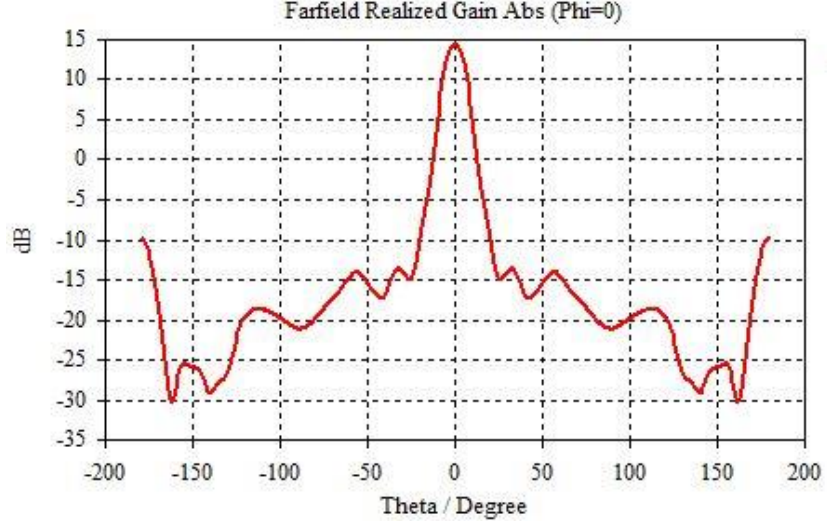

Figure 6 Side Lobe Levels at $15 \mathrm{GHz}$

From simulation results, we also measure power accepted and power radiated of the array antenna. The amount of power accepted by antenna array is $-3.0 \mathrm{~dB}$, which is $0.49 \mathrm{w}$ in linearscale, also power radiated by the antenna is $-3.9 \mathrm{~dB}(0.40 \mathrm{w}$ in linear scale). In Figure 7 , the frequency is set to $15 \mathrm{GHz}$, Main Lob Magnitude $=14.4 \mathrm{~dB}$, main lobe direction=0.0 deg, angular width $(3 \mathrm{~dB})=11.5 \mathrm{deg}$, side lobe level $=-24.3 \mathrm{~dB}$. Furthermore, Figure 7 is the Cartesian 
representation of the radiation pattern and exhibits some information about side lobe level, tuning frequency, main lobe magnitude, and direction. We observe that a side lobe level of $-24.3 \mathrm{~dB}$ is achieved with a gain of $14.4 \mathrm{~dB}$.

Figure 8 shows the plot of radiated efficiency and total efficiency of the antenna array at frequency 15GHz. The radiated efficiency of this array is $-0.92 \mathrm{~dB}(80.8 \%)$ and total efficiency is $-0.94 \mathrm{~dB}$ $(80.3 \%)$.

Figure 9 is the 3D radiation pattern plot of the array antenna, and from this result, we also see the realized gain, which is $14.4 \mathrm{~dB}$ at a frequency of $15 \mathrm{GHz}$.

All simulation results shown previously proves that the presented array antenna shows a good radiation pattern, as well as the efficiencies, powers, and gain, which is also acceptable, which is the critical feature of any antenna. These simulation results will justify the effectiveness of the design. Now we modify the design to operate at $20 \mathrm{GHz}$.
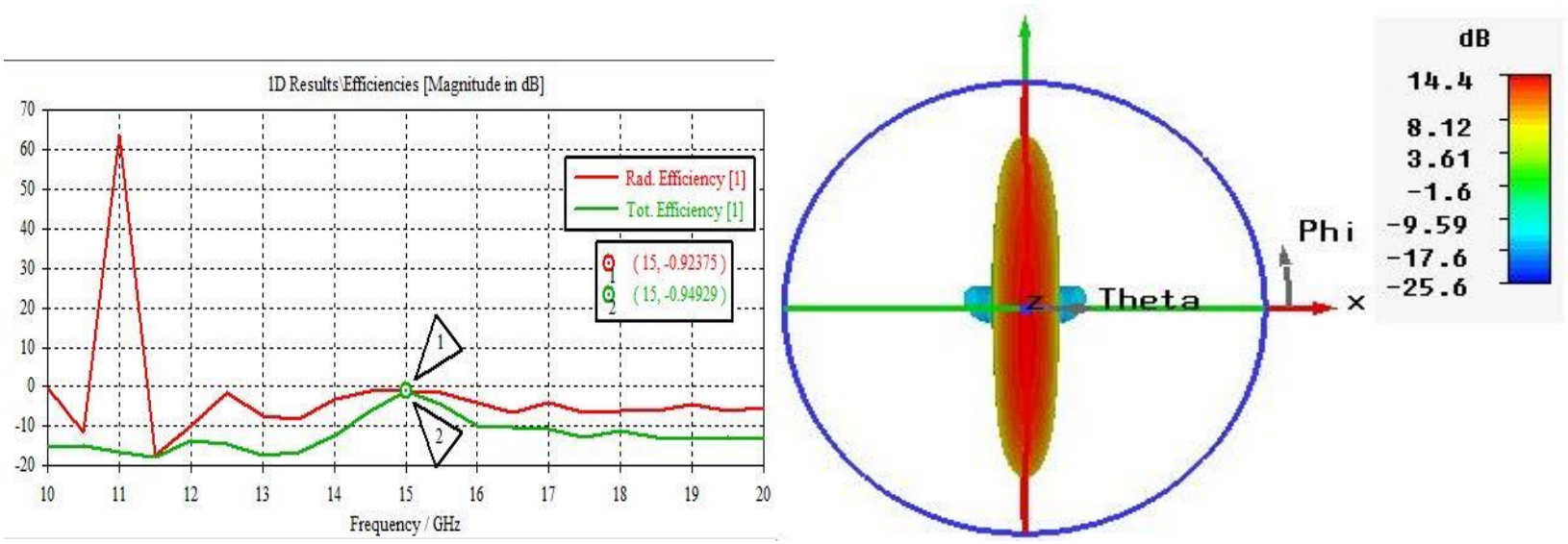

Figure 7 Efficiencies of Antenna Array

Figure 8 Proposed Antenna Array Radiation Pattern

\section{At 20GHz}

From Figure 10, we notice that the proposed array antenna is tuned at frequency $20 \mathrm{GHz}$, and the 
reflected power loss is almost equal to $-14.77 \mathrm{~dB}$. We also find the reflection coefficient $\Gamma=0.18$ in linear scale and VSWR $=1.4$

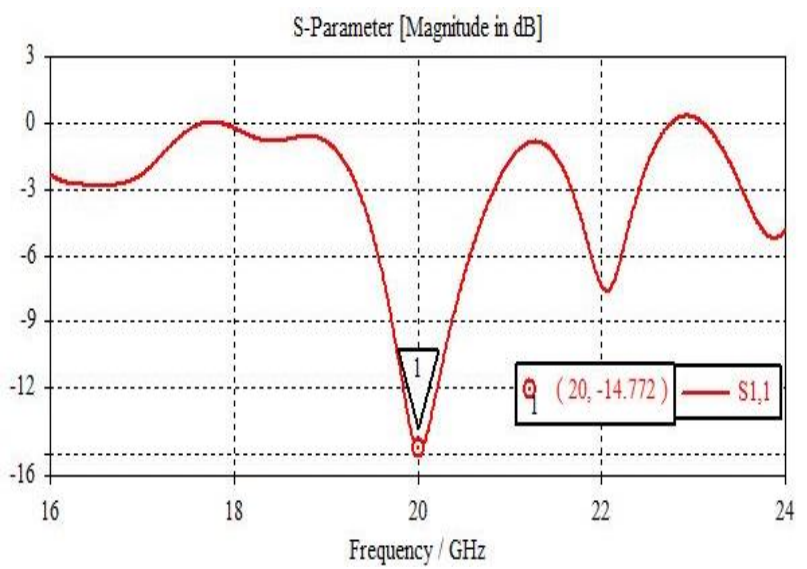

Figure 9 Frequency Response at $20 \mathrm{GHz}$

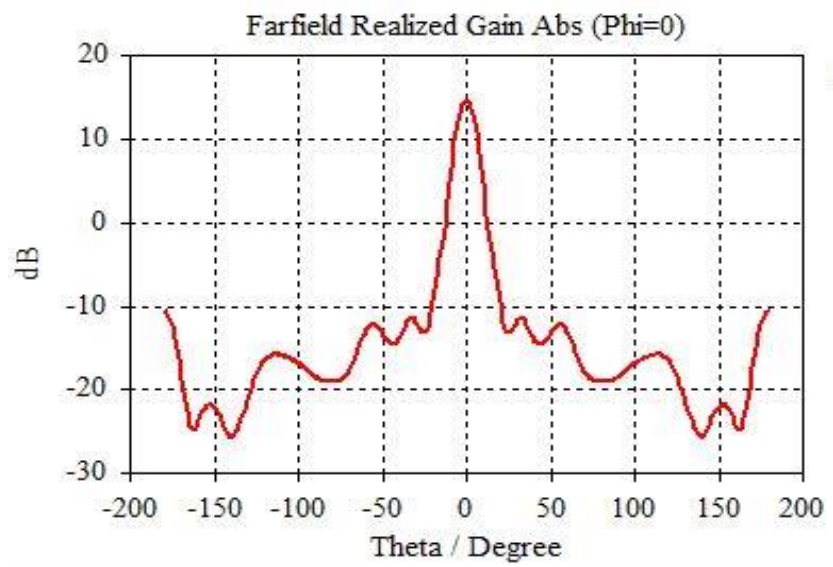

Figure 10 Side Lobe Levels at $20 \mathrm{GHz}$

From simulation results, we also measure power accepted and power radiated of the array antenna. The amount of power accepted by antenna array is $-3.16 \mathrm{~dB}$, which is $0.48 \mathrm{w}$ in linearscale, also power radiated by the antenna is $-3.8 \mathrm{~dB}(0.41 \mathrm{w}$ in linear scale $)$. In Figure 11 , the frequency is set to $20 \mathrm{GHz}$, Main Lob Magnitude $=14.5 \mathrm{~dB}$, main lobe direction=0.0 deg, angular width $(3 \mathrm{~dB})=11.1 \mathrm{deg}$, side lobe level=-25.1 dB. Furthermore, Figure 11 is the Cartesian representation of the radiation pattern and exhibits some information about side lobe level, tuning frequency, main lobe magnitude, and direction. We observe that a side lobe level of $-25.1 \mathrm{~dB}$ is achieved with a gain of $14.5 \mathrm{~dB}$.

Figure 12 shows the plot of radiated efficiency and the total efficiency of the antenna array at 15 $\mathrm{GHz}$ frequency. The radiated efficiency of this array is $-0.64 \mathrm{~dB}(86 \%)$, and total efficiency is $0.79 \mathrm{~dB}(83 \%)$. Figure 13 is the $3 \mathrm{D}$ radiation pattern plot of the array antenna, and from this result, we find the realized gain, which is $14.4 \mathrm{~dB}$ at a frequency of $20 \mathrm{GHz}$. 

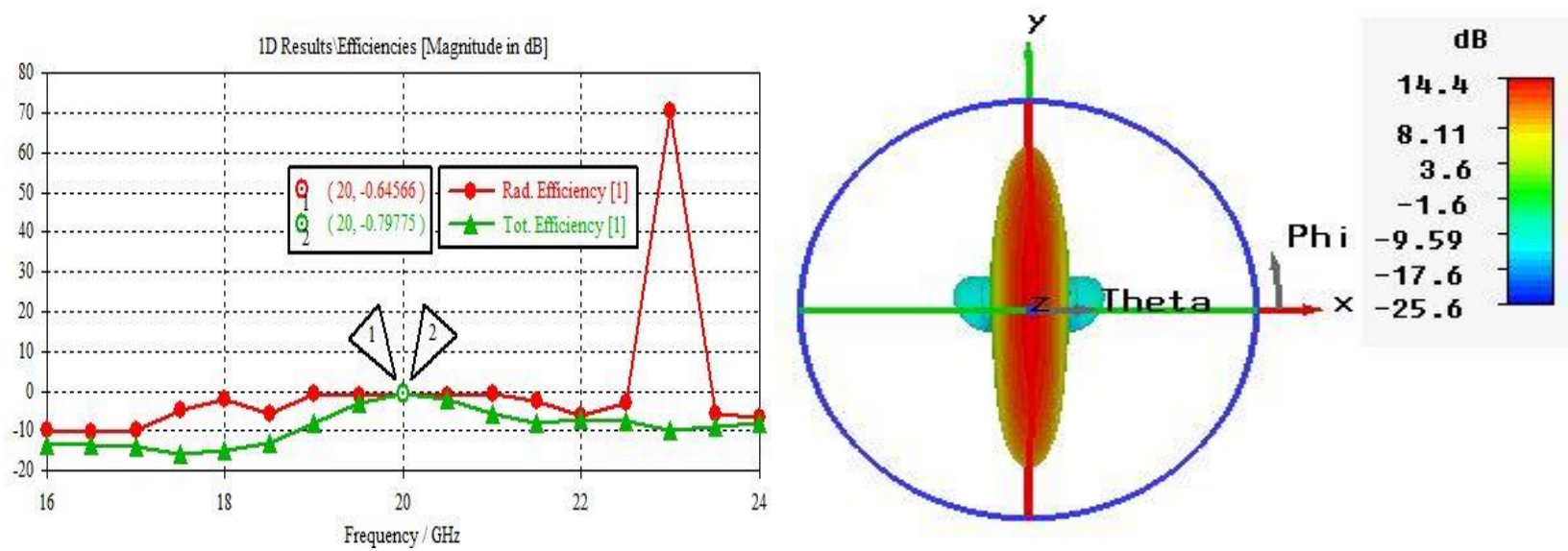

Figure 11 Efficiencies of Antenna Array

Figure 12 Proposed Antenna Array Radiation Pattern Similarly, the simulation results prove that the presented array antenna shows a good radiation pattern, efficiencies, powers, and gain, which are the fundamental parameters of any antenna. Now we modify the design to operate at $24 \mathrm{GHz}$.

\section{At 24GHz}

From Figure 14, we notice that the proposed array antenna is tuned at frequency $24 \mathrm{GHz}$, and the reflected power loss is almost equal to $-30.9 \mathrm{~dB}$. We also find the reflection coefficient $\Gamma=0.028$ in linear scale and VSWR $=1.05$ from this figure.

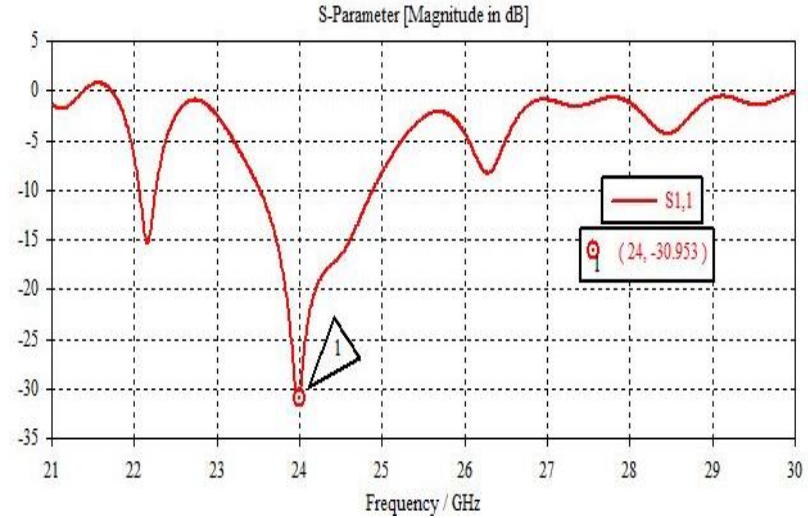

Figure 13 Frequency Response at $24 \mathrm{GHz}$

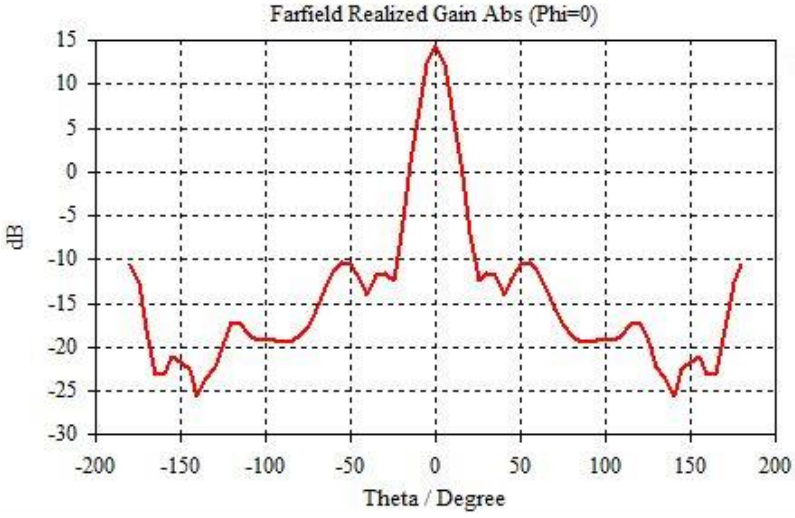

Figure 14 Side Lobe Levels at $24 \mathrm{GHz}$

Simulation results also exhibit the amount of power accepted and radiated of the array antenna.

The amount of power accepted by antenna array is $-3.0 \mathrm{~dB}$, which is $0.49 \mathrm{w}$ in linear-scale, also 
power radiated by the antenna is $-3.4 \mathrm{~dB}(0.44 \mathrm{w}$ in linear scale). In Figure 15 , the frequency is set to $24 \mathrm{GHz}$, Main Lob Magnitude $=14.4 \mathrm{~dB}$, main lobe direction=0.0 deg, angular width $(3 \mathrm{~dB})=$ $11.9 \mathrm{deg}$, side lobe level=-24.7 dB. Furthermore, Figure 15 is the Cartesian representation of the radiation pattern and exhibits some information about side lobe level, tuning frequency, main lobe magnitude, and direction. We observe that a side lobe level of $-24.7 \mathrm{~dB}$ is achieved.

Figure 16 shows the plot of radiated efficiency and total efficiency of antenna array at frequency 15GHz. The radiated efficiency of this array is $-0.41 \mathrm{~dB}(90 \%)$, and total efficiency is $-0.48 \mathrm{~dB}$ $(89 \%)$.
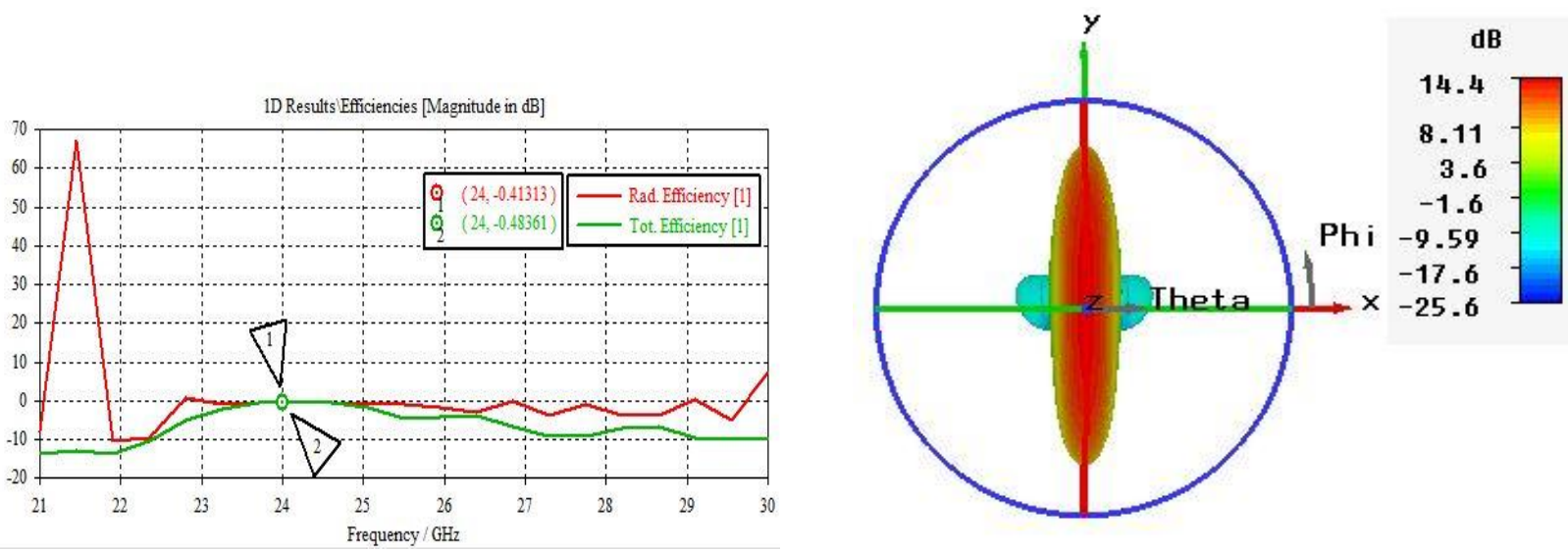

Figure 15 Efficiencies of Antenna Array Figure 16 Proposed Antenna Array Radiation Pattern Figure 17 is the $3 \mathrm{D}$ radiation pattern of the array antenna, and from this result, we find the realized gain, which is $14.4 \mathrm{~dB}$ at a frequency of $24 \mathrm{GHz}$.

All simulation results are showing that the presented array antenna shows a good radiation pattern along with the efficiencies, powers, and gain, which are the critical parameters of any antenna. These parameters will justify the effectiveness of the antenna. All the above results and parameters are summarized in Table 3 for easy understanding. 
Table 3 TABULATED SIMULATION RESULTS

\begin{tabular}{|c|c|c|c|c|}
\hline Parameters & $\mathbf{1 0 G H z}$ & $\mathbf{1 5 G H z}$ & $\mathbf{2 0 G H z}$ & $\mathbf{2 4 G H z}$ \\
\hline Reflected Power Loss & $-18.76 \mathrm{~dB}$ & $-22.5 \mathrm{~dB}$ & $-14.77 \mathrm{~dB}$ & $-30.9 \mathrm{~dB}$ \\
\hline Reflection Coefficient & 0.11 & 0.074 & 0.18 & 0.028 \\
\hline VSWR & 1.26 & 1.16 & 1.4 & 1.05 \\
\hline Power Accepted & $490 \mathrm{mw}$ & $490 \mathrm{mw}$ & $480 \mathrm{mw}$ & $490 \mathrm{mw}$ \\
\hline Power Radiated & $370 \mathrm{mw}$ & $400 \mathrm{mw}$ & $410 \mathrm{mw}$ & $440 \mathrm{mw}$ \\
\hline Radiated Efficiency & $76 \%$ & $80.8 \%$ & $86 \%$ & $90 \%$ \\
\hline Realized Gain & $14.9 \mathrm{~dB}$ & $14.4 \mathrm{~dB}$ & $14.4 \mathrm{~dB}$ & $14.4 \mathrm{~dB}$ \\
\hline Side lobe level & $-24.2 \mathrm{~dB}$ & $-24.3 \mathrm{~dB}$ & $-25.1 \mathrm{~dB}$ & $-24.7 \mathrm{~dB}$ \\
\hline
\end{tabular}

In Table 4, we present a comparison of proposed feed network SLL to the recently proposed design. Different techniques are proposed in these researches as discussed in introduction, with number of antenna elements used for reduction of side lobe. The proposed patch antenna and feed network gives better results by using four elements with simple power divider and weight.

Table 4 comparison table

\begin{tabular}{|c|c|c|c|}
\hline Methodology & $\begin{array}{l}\text { Operating } \\
\text { frequency }(\mathrm{GHz})\end{array}$ & Array elements & Side lobe level \\
\hline $\begin{array}{l}\text { (Smolders \& } \\
\text { Visser, 2014) }\end{array}$ & $3.5-4.5$ & $\begin{array}{l}4 \times 4 \\
8 \times 8 \\
16 \times 16 \\
32 \times 32 \\
\end{array}$ & $\begin{array}{l}\leq-12.3 \mathrm{~dB} \\
\leq-17.8 \mathrm{~dB} \\
\leq-23.4 \mathrm{~dB} \\
\leq-29.5 \mathrm{~dB}\end{array}$ \\
\hline $\begin{array}{l}\text { (Yang et al., } \\
\text { 2019) }\end{array}$ & 24 & $\begin{array}{l}\text { 8x8 planner array } \\
\text { antenna }\end{array}$ & $\leq-21 \mathrm{~dB}$ in both planes \\
\hline $\begin{array}{l}\text { (P. Ji et al., } \\
2020)\end{array}$ & 24 & $\begin{array}{l}\text { 8x8 planner array } \\
\text { antenna }\end{array}$ & $\begin{array}{l}\text { E-plane } \leq-20 \mathrm{~dB} \\
\text { H-plane } \leq-18 \mathrm{~dB}\end{array}$ \\
\hline $\begin{array}{l}\text { (Shin et al., } \\
\text { 2013) }\end{array}$ & 28 & $1 \times 8$ element & Azimuth plane $\leq-20 \mathrm{~dB}$ \\
\hline $\begin{array}{l}\text { Proposed } \\
\text { Method }\end{array}$ & $\begin{array}{l}\text { Multiple } \\
\text { frequencies }(10,15 \text {, } \\
20,24)\end{array}$ & $1 \times 8$ element & $\begin{array}{l}\leq-24.2 \mathrm{~dB} \\
\leq-24.3 \mathrm{~dB} \\
\leq-25.1 \mathrm{~dB} \\
\leq-24.7 \mathrm{~dB}\end{array}$ \\
\hline
\end{tabular}




\section{CONCLUSION}

This unique and simple array antenna was created and simulated for four different frequencies. Patch antenna and an equal power divider are designed to make it is a cost-effective solution in the field of automotive application. A couple of slots in scratch near the edges of the patch and then creating a uniform power divider to distribute power in the feed network equally. To further verify simulation results, an array is simulated at four different frequencies, selected one by one to make it is a scalable design. The SLL achieved is more than $-24.5 \mathrm{~dB}$ at all frequencies in the elevation plane, which is important to minimize false target indication in radars. The results also show that simulated VSWR is equal to $1.26,1.16,1.62$, and 1.05 and the radiation efficiency is equal to $-1.14 \mathrm{~dB},-0.92 \mathrm{~dB},-0.46 \mathrm{~dB},-0.41 \mathrm{~dB}$ at selected frequencies. All simulation results show that the proposed array antenna has a good radiation pattern at all selected frequencies along with the radiated efficiency, radiated power, and gain, which are the fundamental parameters of any antenna. These simulations will justify the effectiveness and scalability of the design. This design can be enhanced to suppress the side lobe level as per requirement. Due to its compact and feasible size, it can be used as a radar antenna in autonomous vehicle technology. 


\section{REFERENCES}

Ahn, H.-R., \& Tentzeris, M. M. (2019). In-Phase T-Junction: Study and Application to Gysel Power Dividers for High Power-Division Ratios Requiring No High-Impedance Transmission-Line Section. IEEE Access, 7, 18146-18154.

Anandkumar, D., \& Sangeetha, R. G. (2020). Design and analysis of aperture coupled micro strip patch antenna for radar applications. International Journal of Intelligent Networks, 1, $141-147$.

Chen, H., Zhang, T., Che, W., \& Feng, W. (2014). Compact unequal Wilkinson power divider with large power dividing ratio. 2014 9th European Microwave Integrated Circuit Conference, $608-611$.

Contreras, S., \& Peden, A. (2013). Graphical design method for unequal power dividers based on phase-balanced SIW tee-junctions. International Journal of Microwave and Wireless Technologies, 5(5), 603-610.

Gasztold, M. (2014). An antenna array with a high division ratio Wilkinson power dividers. 2014 20th International Conference on Microwaves, Radar and Wireless Communications (MIKON), 1-5.

Jamshid, J., Abbasi, T., Khan, A. K., \& Rizvi, Z. A. (2017). Uniform power distribution for low side lobe automotive applications at $24 \mathrm{GHz}$. 2017 International Conference on Open Source Systems Technologies (ICOSST), 42-47. 
Ji, J., Wang, C., Wu, X., \& Zhou, J. (2020). A K/Ka Dual-band Continuous Transverse Stub (CTS) Antenna Array With Sidelobe Suppression. 2020 IEEE International Symposium on Antennas and Propagation and North American Radio Science Meeting, 3-4.

Ji, P., Qi, Z., Huang, X., Zhao, W., Zhu, Y., \& Li, X. (2020). K-Band Wideband Microstrip Antenna Array With Sidelobe Level Reduction. 2020 International Conference on Microwave and Millimeter Wave Technology (ICMMT), 1-3.

Karimi, P., \& Maddahali, M. (2018). Wideband Slotted Array Antenna Based on Substrate Integrated Waveguide with Circular Aperture at Ka-Band. 2018 9th International Symposium on Telecommunications (IST), 5-10.

Li, J.-Y., Qi, Y.-X., \& Zhou, S.-G. (2017). Shaped Beam Synthesis Based on Superposition Principle and Taylor Method. IEEE Transactions on Antennas and Propagation, 65(11), 6157-6160.

Liu, Y., Wang, H., Li, K., \& Gong, S. (2015). RCS Reduction of a Patch Array Antenna Based on Microstrip Resonators. IEEE Antennas and Wireless Propagation Letters, 14, 4-7.

Oborzhytskyy, V., \& Prudyus, I. (2016). The design of microwave planar power dividers and couplers with distinct power division ratio in two different frequency bands. 2016 International Conference Radio Electronics Info Communications (UkrMiCo), 1-3.

Park, S.-J., Shin, D.-H., \& Park, S.-O. (2016). Low Side-Lobe Substrate-Integrated-Waveguide Antenna Array Using Broadband Unequal Feeding Network for Millimeter-Wave Handset Device. IEEE Transactions on Antennas and Propagation, 64(3), 923-932. 
Quan, Y., Yang, J., Wang, H., \& Zaman, A. U. (2021). An unequal power divider based on ridge gap waveguide with an inserted conductor plate. Microwave and Optical Technology Letters, $63(2), 443-449$.

Rabbani, M. S., \& Ghafouri-Shiraz, H. (2017). Evaluation of gain enhancement in large microstrip antenna arrays for mm-wave applications. 1 (5 .)-1 (5 .).

Rajeswari, P., \& Anbalagan, P. (2020). Design and deployment of android based mobile application for performance analysis of micro strip patch antenna. Microprocessors and Microsystems, 77, 103111.

Shin, D., Kim, K., Kim, J., \& Park, S. (2013). Design of low side lobe level milimeter-wave microstrip array antenna for automotive radar. 2013 Proceedings of the International Symposium on Antennas Propagation, 02, 677-680.

Smolders, A. B., \& Visser, H. J. (2014). Low Side-Lobe Circularly-Polarized Phased Arrays Using a Random Sequential Rotation Technique. IEEE Transactions on Antennas and Propagation, $62(12), 6476-6481$.

Sohail, A., Alimgeer, K. S., Iftikhar, A., ljaz, B., Kim, K. W., \& Mohyuddin, W. (2018). Dual notch band UWB antenna with improved notch characteristics. Microwave and Optical Technology Letters, 60(4), 925-930.

Wang, H., Kedze, K. E., \& Park, I. (2018). Microstrip Patch Array Antenna Using a Parallel and Series Combination Feed Network. 2018 International Symposium on Antennas and Propagation (ISAP), 1-2. 
Yang, H., Li, T., Xu, L., Cao, X., Gao, J., Tian, J., Yang, H., \& Sun, D. (2019). A New Strategy to Design Microstrip Antenna Array With Low Side-Lobe Level and High Gain. IEEE Access, 7, 152715-152721. https://doi.org/10.1109/ACCESS.2019.2948098 